\title{
DIREITO À EDUCAÇÃO E PANDEMIA: REFLEXÕES SOBRE UM ESTADO PARA DIREITOS NO BRASIL
}

\author{
Renata Caroline Pereira Reis* \\ Viviane Freitas Perdigão Lima**
}

\section{RESUMO}

Partindo-se do direito à educação como direito social de segunda dimensão analisa-se este direito social durante as medidas adotadas pelo Brasil durante o estado de calamidade pública instalado pelo coronavírus. A metodologia é descritiva e exploratória com abordagem qualitativa de documentos afetos à educação no Brasil. O referencial teórico fundamenta-se na democracia garantista na ideia de estado para os direitos compreendidos como razão social a garantia dos direitos sociais estipulados como vitais pelas normas substanciais. (COPETTI NETO, 2016). Observa-se que os desafios causados pela pandemia precisam ser enfrentados para se assegurar a continuidade e qualidade dos serviços educacionais públicos.

Palavras-chave: Coronavírus; Direito à educação; Democracia substancial; Serviços educacionais; Qualidade.

\section{RIGHT TO EDUCATION AND PANDEMIC: REFLECTIONS ON A STATE FOR RIGHTS IN BRAZIL}

\begin{abstract}
tarting from the right to education as a second dimension social right, this social right is analyzed during the measures adopted by Brazil during the state of public calamity installed by the coronavirus. The methodology is descriptive and exploratory with a qualitative approach to documents related to education in Brazil. The theoretical framework is based on guaranteeist democracy on the idea of the state for rights understood as social reason, the guarantee of social rights stipulated as vital by substantial norms. (COPETTI NETO, 2016). It is observed that the challenges caused by the pandemic need to be faced to ensure the continuity and quality of public educational services.
\end{abstract}

Keywords: Coronavirus; Right to education; Substantial democracy; Educational services; quality.

\section{INTRODUÇÃO}

O panorama mundial de emergência sanitária decorrente da pandemia do coronavírus (COVID-19), mostrou alterações na rotina e nos hábitos, instalando um estado de crise(s). Dentre a das medidas recomendadas pela Organização das Nações Unidas e adotada pelo

\footnotetext{
* Doutoranda em Direito (UNESA). Mestra em Cultura e Sociedade (UFMA). Especialista em Direito Público. Advogada. Professora do curso de Direito do Centro Universitário Estácio São Luís. São Luís/MA. E-mail: renatacpreis@hotmail.com

** Mestra em Direito e Instituições do Sistema de Justiça (UFMA). Professora da Universidade Estadual do Maranhão. Advogada. São Luís/MA. E-mail: viperdigao@gmail.com.
} 
governo dos países de todo o mundo foi o de suspender as aulas presenciais, na educação básica e superior, pública e privada, haja vista a necessidade de distanciamento social, a fim de se tentar efetivar, pelo menos em certa medida, o controle da taxa de transmissão e expansão da doença e a preservação da saúde e vida da população.

Diante dessa realidade, uma série de medidas sanitárias e legais foram adotadas pelos órgãos educacionais dos Estados para regulamentar e possibilitar a retomada das atividades de ensino formal. Por entender que cada país se comportou (e ainda se comporta) possivelmente de maneira diferenciada e particular, a depender da realidade de cada localidade, da situação econômica, de saúde, de condições de acesso e permanência na escola, acesso às plataformas digitais, internet e meios de comunicação, etc., a pesquisa volta-se para a temática do direito à educação, com vistas a levantar e indicar os aspectos e ações implantadas, do ponto de vista legal por países da América Latina.

Para esta pesquisa, levou-se em consideração, em relação ao universo, a seleção de países localizados nesse recorte, considerando-se, em específico, o aspecto do índice de desenvolvimento humano colacionado pelo Programa das Nações Unidas para o Desenvolvimento (PNUD), de 2019 (PNUD, 2019). Portanto, definiu-se o Brasil, em razão do critério da origem das pesquisadoras com o fim de observar em que medida as ações adotadas no campo do direito à educação, cuidando da educação básica, em sentido amplo, se ainda assim se analisa o Brasil como um estado para direitos em que a garantia de direitos sociais deve ser estipulada como vitais diante de suas normas substanciais.

Pretendeu-se, portanto, responder ao seguinte questionamento: Quais ações do ponto de vista normativo têm sido realizadas para garantir o direito à educação no Brasil selecionados durante o contexto emergencial instalado pelo coronavírus?

De modo geral, buscou-se descrever as determinações normativas expedidas pelo Brasil voltadas para assegurar o direito humano fundamental à educação após a suspensão de aulas em decorrência da pandemia do COVID-19. Além de qual(is) políticas públicas têm sido adotadas pela amenizar o contexto excepcional caraterizado pelas demandas perpetradas pela Covid-19. Especificamente, caracterizou-se o direito à educação, perpassando por documentos emitidos por organismos internacionais. Também se identificou os documentos emitidos pelos países selecionados Brasil voltados para o contexto da educação formal durante a pandemia do coronavírus, descrevendo e analisando as ações enunciadas. 
Como referencial teórico a pesquisa parte da proteção do direito à educação como um direito social perpetrado a partir de uma dimensão substancial da democracia no qual a democracia social está sob a batuta do garantismo jurídico onde se pretendeu diminuir a exposição maciça e dependência dos direitos sociais à discricionaridade administrativa ou a regra da maioria. (COPETTI NETO, 2016).

Para a realização desta pesquisa, utilizou-se da pesquisa exploratória e descritiva, de cunho bibliográfico e documental, com a seleção de autores e normas relacionadas ao tema investigada (GIL, 2008). Utilizou-se como base o método dialético, uma vez que se pretendeu realizar uma leitura crítica do Direito, posto o seu reconhecimento, conforme pondera Lyra Filho (1980), enquanto um processo histórico e em permanente construção. O texto está dividido em três seções. Na primeira analisa-se o direito à educação em um contexto de direitos humanos fundamentais consubstanciados dos diplomas constitucionais. Na segunda, a educação básica e ações normativas durante a pandemia do COVID-19 no Brasil. Ao cabo visa-se refletir o contexto educacional pandêmico no Brasil e a busca de um estado para o direito social à educação. Observa-se que os desafios causados pela pandemia precisam ser enfrentados para se assegurar a continuidade e qualidade dos serviços educacionais públicos.

\section{DIREITO À EDUCAÇÃO: UM COMPONENTE PARA O DESENVOLVIMENTO HUMANO}

Apresentar uma conceituação para direitos humanos fundamentais*, no contexto contemporâneo, mostra-se enquanto um exercício complexo. Posto que a sua enunciação envolve embates ideológicos, sociais e políticos, de modo que não é possível se pontuar uma definição única. Ademais, são estes direitos relativos, históricos e diversificados, não sendo possível a atribuição de um fundamento que lhe seja absoluto (BOBBIO, 2004), partindo-se de perspectivas filosóficas, éticas, políticas, históricas, culturais, etc.

Tratando-se de direitos sócio-historicamente elaborados, a sua abordagem perpassa por sua multidimensionalidade, o que demonstra a opção pela expressão "dimensões de direitos" por vê-los enquanto interdependentes e indivisíveis, tal qual adotado por Sarlet (2012). Nesse contexto, o direito humano fundamental à educação integra a segunda

\footnotetext{
${ }^{*}$ Nesta pesquisa, adotou-se a expressão direitos humanos fundamentais adorada por Ferreira Filho (2009) e por Ramos (2015), por considerar que os valores que integram a conceituação são intrínsecos e ultrapassam a discussão e segregação que afastaria a ideia de direitos humanos (contexto internacional) e direitos fundamentais (âmbito interno de cada nação).
} 
dimensão de direitos, voltado ao aspecto social que integra aqueles que ascenderam no contexto da Revolução Industrial e dos cenários de lutas contra as mazelas sociais suportadas pelos menos favorecidos, vulneráveis.

Assim, os direitos sociais "se realizam pela execução de políticas públicas, destinadas a garantir amparo e proteção social aos mais fracos e mais pobres; ou seja, aqueles que não dispõem de recursos próprios para viver dignamente" (COMPARATO, 2010, p. 77). Ou seja, objetivam assegurar aos indivíduos o mínimo de condições para o exercício e gozo dos seus direitos, com vistas a diminuir as desigualdades sociais.

Trata-se de uma prestação positiva do Estado, haja vista o compromisso que este deve estabelecer com a função social, com as condições dignas de existência e igualdade. Nas palavras de Dias (2007, p. 447), “Cabe, portanto, ao Estado se aparelhar para viabilizar a consecução do direito à educação. Todas as demais normas do sistema educacional, devem ser interpretadas com o fim precípuo de efetivar a realização plena do direito à educação".

A bem da verdade, o direito à educação apresenta-se enquanto um pré-requisito indispensável para que alguém possa ter condições de acesso e usufruto dos demais direitos civis, políticos e sociais. Não sendo possível desconfigurar o seu papel relevante enquanto componente elementar para os direitos humanos.

Este é um direito elucidado em documentos internacionais e também internalizado na carta política das nações. No contexto internacional, a Declaração Universal dos Direitos Humanos (DUDH), da Organização das Nações Unidas, de 1948, apresenta, no artigo 26, que

1. Todos os seres humanos têm direito à educação. A educação será gratuita, pelo menos nos graus elementares e fundamentais. A educação elementar será obrigatória. A educação técnico-profissional será acessível a todos, bem como a educação superior, está baseada no mérito.

2. A educação será orientada no sentido do pleno desenvolvimento da personalidade humana e do fortalecimento do respeito pelos direitos humanos e pelas liberdades fundamentais. A educação promoverá a compreensão, a tolerância e a amizade entre todas as nações e grupos raciais ou religiosos, e coadjuvará as atividades das Nações Unidas em prol da manutenção da paz.

3. Os pais têm prioridade de direito na escolha do género de educação que será ministrada aos seus filhos.

Outro documento a ser destacado é o Pacto Internacional Sobre Direitos Econômicos, Sociais e Culturais, de 1966. Este trata da educação reconhecendo o seu papel de colaboração para o desenvolvimento, o respeito e a dignidade humana. $\mathrm{O}$ artigo 13 acrescenta ainda que, por meio desta, é que os indivíduos são habilitados para o desempenho de uma 
conduta útil e para que uma sociedade livre seja construída, mantendo-se a paz e promovendo a tolerância e o respeito. O que corrobora com o que é apresentado pela DUDH.

A Recomendação da UNESCO sobre a Educação para a Compreensão, Cooperação e Paz Internacionais e a Educação Relativa aos Direitos Humanos e Liberdades Fundamentais (1974), ao ser anunciada pela Organização das Nações Unidas para a Educação, a Ciência e a Cultura (UNESCO), definiu terminologias, dentre estas, se ocupou com a educação, considerando-a enquanto um processo integral que desenvolve capacidades, atitudes, conhecimentos e aptidões em geral.

No contexto sul-americano, o direito à educação passou a ser consubstanciado nas cartas políticas e legislações infraconstitucionais, de modo a acompanhar os delineamentos sociais e políticos, bem como os tratados e convenções internacionais. Quer dizer, os países buscaram modelos educacionais que melhor se ajustassem aos projetos econômicos de desenvolvimento e em sua própria realidade social, consolidando-se a partir da efetivação do Estado Democrático de Direito ou o Estado Social de Direito.

A educação, no ano de 2020, se deparou com um contexto de crise(s) que abalou as estruturas de todos os países, após a detecção, em Wuhan, China, de um novo vírus com alto poder de contágio, o SARS-CoV-2, também chamado de coronavírus (COVID-19) e reportada à Organização Mundial de Saúde (OMS), em 31 dezembro de 2019. O alto risco de contágio, o resultado morte e as inúmeras complicações, incluindo pneumonia, síndrome respiratória aguda grave, insuficiência renal, além de febre, cansaço, tosse seca, congestão nasal, dor de garganta e diarreia, dores no corpo e na cabeça (HUANG et al, 2020), conduziram a determinação de distanciamento social, afetando o sistema educacional de ensino, com o fechamento das instituições de ensino em todo o mundo.

Esta situação se deu pelo fato de que, em 30 de janeiro de 2020, a OMS declarou o surto do coronavírus como Emergência de Saúde Pública de Importância Internacional (OMS, 2020) e, em razão da conjuntura crescente e assustadora do contágio, em 11 de março de 2020, declarou-se o status de pandemia. Diante desse quadro é que se passa a identificar como o Brasil se comportou e quais documentos/diretrizes indicaram para a manutenção da educação básica formal durante a pandemia do COVID-19.

\section{EDUCAÇÃo BÁSICA E AÇÕES NORMATIVAS DURANTE A PANDEMIA DO COVID-19 NO BRASIL}


Dado o contexto estabelecido pela pandemia do coronavírus, em 04 de fevereiro de 2020, o Ministério de Saúde do Brasil publicou a Portaria nº 188, declarando Emergência em Saúde Pública Nacional em decorrência da infecção humana pelo coronavírus (BRASIL, 2020). Portanto, em razão da necessidade de distanciamento e, consequentemente, do fechamento das instituições de educação, questões relacionadas a garantia do direito à educação, seu acesso, permanência e qualidade ganharam evidência. Afinal, o quadro instalado coloca o direito à vida e à saúde em conflito com o direito à educação, intrinsecamente ligado à dignidade humana.

Parte-se do entendimento de que, seguindo um movimento de internalização dos direitos humanos fundamentais, a Constituição da República Federativa do Brasil (BRASIL, 1988) trata da educação quando da abordagem dos direitos fundamentais sociais, apresentando-a no artigo sexto. Assim, visando formas de concretizar tal direito, o artigo 205, da Carta Política do país estabelece que a educação é um direito de todos e responsabilidade da família, da sociedade e do Estado, devendo este criar estratégias que proporcionem a construção de uma sociedade mais igualitária, solidária e livre de preconceitos.

Pelo que se vê, em linhas gerais, a educação, no Brasil, é um direito constitucionalmente enunciado, a ser promovido com vistas a alcançar a todos, integrando o mínimo existencial para a realização da dignidade da pessoa humana, atribuindo ao Estado o dever de prover as condições para o seu pleno exercício. Razão pela qual as normas legislativas também têm sido elaboradas visando assegurar o acesso universal e gratuito, a igualdade de condições do aprendizado, a qualidade de ensino, além de outras metas educacionais.

Nessa perspectiva, a Lei de Diretrizes e Bases da Educação - Lei no 9.394/1996 (BRASIL, 1996) estabelece, no artigo 24, um mínimo anual de 200 dias letivos e 800 horas de efetivo trabalho escolar. Por seu turno, a Base Nacional Curricular Comum (BNCC) indica competências e objetivos de aprendizagens a serem atendidos. A situação de suspensão de aulas inaugura um verdadeiro desafio no que tange a garantia de continuidade do desenvolvimento educacional dos educandos com qualidade para que esses possam compreender o mundo, suas transformações e o papel que ocupam enquanto sujeitos nesse processo (BRASIL, 2018).

A partir dessa realidade, os órgãos de educação federal, estadual, municipal e distrital, no Brasil, editaram normas voltadas a regulamentar a continuidade e oferta do ensino 
durante o período de pandemia do COVID-19. Em observância ao objetivo proposto, esta pesquisa se ocupará, em específico, com a educação básica regular e pública.

Há que se observar que, antes de qualquer edição de resolução ou parecer pelo Conselho Nacional de Educação, no tocante à Educação Básica Regular (que no Brasil, de acordo com o artigo $4^{\circ}$, da LDB, é obrigatória e gratuita e envolve a educação infantil, ensino fundamental e ensino médio. alguns municípios e estados através de seus respectivos conselhos editaram normativas orientando as instituições de ensino pertencentes aos seus sistemas sobre a reorganização do calendário escolar e o uso de atividades não presencias, em virtude da pandemia. Contudo, em que pese a autonomia de cada ente, o Conselho Nacional de Educação e o MEC, a fim de se ter uma diretriz a nível nacional precisou se manifestar, permitindo maior confluência de mecanismos para minimizar os impactos da pandemia na educação, principalmente no tocante à educação infantil.

A princípio, não se comportaria nessa etapa de ensino a atividade não-presencial, pairando dúvidas também quanto à validação das atividades letivas não presenciais, sendo certo que, apesar da autonomia dos sistemas de ensino, o Conselho Nacional de Educação, tem competência para se manifestar quanto às questões que envolvam mais de uma modalidade de Ensino (BRASIL, 1961). Este é o entendimento disposto no artigo $7^{\circ}$ da Lei $n^{\circ}$

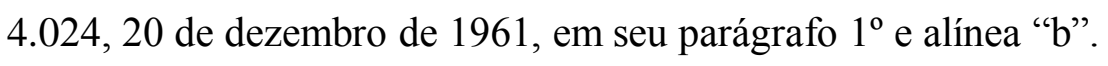

Assim, a Medida Provisória de $\mathrm{n}^{\circ} 934$, de $1^{\circ}$ de abril de 2020, editada pelo Governo Federal, foi um dos primeiros instrumentos elaborados, de caráter nacional, visando dar alguma diretriz aos entes, no tocante às atividades educacionais no ensino básico (BRASIL, 2020). Esta medida estabeleceu normas excepcionais sobre o ano letivo da educação básica e do ensino superior decorrente das medidas de enfrentamento da situação de emergência em saúde pública, dispondo em seu artigo $1^{\circ}$, sobre a dispensa, em caráter excepcional, do cumprimento obrigatório dos 200 dias letivos de efetivo trabalho escolar. O que representou uma verdadeira flexibilização ao que determina a LDB, mantendo-se, entretanto, a obrigação das 800 horas, não esclarecendo as condições para o seu cumprimento.

Por seu turno, o Conselho Nacional de Educação elaborou o Parecer CNE/CP de $n^{\circ}$ 05/2020, aprovado em 28 de abril de 2020, sendo parcialmente homologado pelo MEC (BRASIL, 2020a). Este foi objeto de reexame, gerando o parecer CNE/CP de nº 09/2020. Para a sua elaboração, o parecer considera as normativas formuladas pelo MEC, em nível federal, pelos Conselhos Estaduais e Municipais de Educação, sendo também realizada a 
consulta pública, contando com contribuições de diversas organizações públicas e privadas e de pais de alunos da educação básica (BRASIL 2020b, pp 2-3).

As contribuições também vieram da União Nacional dos Dirigentes Municipais de Educação (UNDIME), do Conselho Nacional dos Secretários Estaduais de Educação (CONSED), da União dos Conselhos Municipais de Educação (UNCME) e do Fórum Nacional dos Conselhos Estaduais de Educação (FNCE) (BRASIL 2020b). Acredita-se que foi importante a contribuição das mais variadas fontes, posto que se está cuidando da regulamentação de um direito humano fundamental.

Dentre outros aspectos, o referido parecer enfrentou questões pertinentes ao cômputo das atividades letivas não presenciais nas diversas modalidades de ensino, bem como a reorganização do calendário letivo, observando-se o caráter orientador do parecer, resguardando a autonomia dos Sistemas de Ensino, bem como as particularidades de cada localidade. Nesta perspectiva, o parecer reforça o cuidado com os direitos e objetivos da aprendizagem, a preocupação com o não-retrocesso no aprendizado dos alunos, a impossibilidade de se cumprir o calendário de 2020 de forma presencial, impactando no comprometimento do calendário de 2021.

Um aspecto que merece atenção também é o reconhecimento da possibilidade de se trabalhar, no ano de 2021, concomitantemente, parte do conteúdo de 2020, que não tenha sido ministrado durante esse ano letivo. Vê-se uma preocupação com o aumento das desigualdades e da evasão escolar com a perda do contato entre a escola e os educandos(as).

Destaca-se que este parecer foi elaborado no mês de abril de 2020, no início da situação emergencial e, diante da incerteza de duração da necessidade de manutenção do fechamento das unidades escolares. Naquele momento, orientou-se que a reorganização dos calendários contivesse a possibilidade de reposição das atividades de forma presencial, quando cessada a situação de emergência, em conjunto com as atividades não presenciais.

Mostrou-se uma preocupação em se buscar alternativas para a redução da necessidade de reposição da carga horária de forma presencial, em caso de um período logo de suspensão das atividades presencias, o que acabou ocorrendo. Afinal, está-se no mês de dezembro e a maior parte das instituições de ensino do país se encontram fechadas. Neste sentido o referido parecer traz a possibilidade de validar a realização de atividades pedagógicas não presenciais para a composição da carga horária necessária. 
O item 2.6 (BRASIL, 2020b, p. 8) registra que as atividades pedagógicas, durante o período de suspensão das atividades presenciais, deverão ser mediadas por práticas pedagógicas que utilizem ou não tecnologias digitais de informação e comunicação. É necessário que estas práticas promovam o desenvolvimento de objetivos de aprendizagem, de habilidades, o currículo e as propostas recomendadas pela BNCC.

Com base neste dispositivo, observa-se a permissão para a utilização de diversos mecanismos que corroborem para assegurar o direito à educação. O uso de plataformas de ensino, aplicativos, programas de televisão, rádio, mídias e redes sociais, canais no youtube, material impresso, etc. O que deve ser observado é a garantia da qualidade e acesso, portanto, quanto mais variadas forem as possibilidades de ferramentas, maiores serão as possibilidades de alcançar o maior número de alunos, haja vista a existência de realidades e condições sociais distintas.

Em 07 de julho de 2020c, o Conselho Nacional de Educação aprovou o Parecer CNE/CP de $n^{\circ}$ 11/2020, homologado parcialmente pelo MEC em 03 de agosto de 2020, tendo em vista a necessidade de reexame do item 8 do parecer (BRASIL, 2020c). Este tratou de orientações para a realização de atividades presenciais e não presenciais durante a pandemia, em complementação ao parecer 05/2020.

Assim como o parecer anterior, este novo também possuiu caráter opinativo e sugestivo, trabalhando a temática de uma possível retomada das voltas às atividades presenciais. Cumpre destacar que este parecer traz uma análise diagnóstica da situação da educação básica, mencionado as pesquisas realizadas pela Fundação Roberto Marinho, através do Projeto Retomada Juntos, Undime, Itaú Social, Unicef, Plano CDE e Cieb com o desafio das Secretarias Municipais de Educação, Instituto Unibanco e Todos pela Educação, Data Folha.

As pesquisas mencionadas permitiram ter uma perspectiva da ocorrência da aplicação de atividades não presencias pelos entes, do acesso de alunos a esta atividades nas suas mais diversas formas, bem como se estava ocorrendo ou não a preparação para o retorno seguro às atividades presenciais.

Vale mencionar que o Instituto Rui Barbosa, juntamente com 22 Tribunais de Contas Estaduais, 03 Tribunais de Contas com jurisdição exclusiva e 01 Tribunal de Contas municipal, elaborou o Projeto "A Educação não pode esperar", realizando pesquisa a fim de auxiliar as redes e profissionais da educação neste momento de pandemia (INSTITUTO RUI 
BARBOSA, 2020). O estudo realizado por este instituto visou abordar a aplicação das atividades não presenciais em 232 redes de Ensino municipal e 17 estaduais, sendo certo que esta pesquisa procurou abranger desde a forma de realização das atividades não presencias, até a questão de distribuição de alimentos, perpassando pela preparação de retomada das atividades presencias, procurando abarcar as cinco regiões do país.

As pesquisas realizadas podem ser consideradas relevantes mecanismos para a percepção da efetivação das medidas adotadas para a garantia do direito à educação. Posto que demonstra um esforço coletivo para que se tenham balizadores dos enfrentamentos a serem realizados nessa difícil tarefa que é readequar os sistemas de ensino em período pandêmico e pós-pandêmico.

Outro destaque é dado, que em virtude das peculiaridades atinentes à esta pandemia, para a edição da Lei 14.040, de 18 de agosto de 2020, publicada no Diário Oficial da União, de 19 de agosto de 2020. Esta lei estabelece normas educacionais excepcionais a serem adotadas durante o estado de calamidade pública pelo Decreto Legislativo $\mathrm{n}^{\circ} 6$, de 20 de março de 2020 e alterou a Lei $n^{\circ} 11.947$, de 16 de junho de 2009.

Desta feita, a referida Lei atribui ao Conselho Nacional de Educação, em caráter de excepcionalidade, competência para editar, diretrizes nacionais, para os Sistemas de Ensino (BRASIL, 2020). Observa-se que a nova legislação faz nascer a necessidade do Conselho Nacional de Educação editar, não mais um Parecer sugestivo ou opinativo, mas uma norma fixando as diretrizes a serem observadas, de acordo com a Lei 14.040 de 2020.

É nesse contexto que o CNE elaborou o parecer de no 15/2020 (BRASIL, 2020d), aprovado pelo colegiado em 06 de outubro de 2020, que contém o projeto de Resolução que institui Diretrizes Nacionais orientadoras para a implementação dos dispositivos da Lei $n^{\circ}$ 14.040/2020. O parecer estabelece normas educacionais excepcionais a serem adotadas pelos sistemas de ensino, instituições e redes escolares, públicas, privadas, comunitárias e confessionais, durante o estado de calamidade reconhecido pelo Decreto Legislativo $\mathrm{n}^{\mathbf{o}}$ 6/2020, que segue aguardando homologação pelo MEC.

Nas pesquisas realizadas, não se encontrou, por parte do Governo Federal, uma destinação de recursos diretos aos Estados e Municípios para as redes de ensino, na aplicação das atividades letivas não presenciais. Quer dizer, não há uma destinação para aquisição de equipamentos de informática, fornecimento de rede internet, dentre outros mecanismos que poderiam ser utilizados a fim de atendimento a um maior número de estudantes e também de 
subsidiar aos profissionais envolvidos na educação maiores ferramentas para ministrar o ensino.

\section{A EDUCAÇÃO NO CONTEXTO PANDÊMICO NO BARSIL: EM BUSCA DE UM ESTADO PARA DIREITO SOCIAL À EDUCAÇÃO}

Dados de 2020 sobre a educação básica no Brasil apontavam a existem no Brasil 179.533 escolas de educação básica e 2.189.005 docentes, além de haver 70,9 mil creches no país. Tal era o contexto anterior à pandemia causada pela Covid-19. O desafio atual é saber como está sendo a educação dos 8.829.795 alunos na educação infantil; 26.718 .830 no ensino fundamental; 7.550.753 matriculados no ensino médio; 1.936 .094 no médio técnico; e 1,3 milhão dentro da educação especial apontados pelos dados do Censo da Educação Básica de 2020, elaborado pelo Instituto Nacional de Estudos e Pesquisas Educacionais Anísio Teixeira (INEP, 2020).

O Censo de 2020 demonstrava que a rede municipal havia o maior número de estudantes contendo 48,4\% das matrículas na educação básica. Já no âmbito estadual havia a concentração de $95,9 \%$ dos alunos da rede pública. Cabia à rede federal apenas $1 \%$ do total dos discentes. Tal era o panorama anterior a contaminação pela Covid-19 (INEP, 2020).

Diante da excepcionalidade vivenciada pela pandemia de COVID-19, o Conselho Nacional de Educação - CNE editou o Parecer n ${ }^{\circ}$ 05/20, o qual analisa a reorganização dos calendários escolares e a realização de atividades pedagógicas não presenciais em razão da pandemia da COVID-19. A intenção do CNE é traçar diretrizes gerais e sugerir ações a serem atendidas pelas instâncias cabíveis a nível estadual e municipal em defesa ao direito à educação, quais sejam: os sistemas de ensino e conselhos de educação.

Em vista dessa permissividade obtida pelo CNE, os Conselhos Estaduais de Educação - CEEs e os Conselhos Municipais de Educação - CMEs assam a apresentar cero protagonismos na regulamentação e reorganização dos calendários escolares dentro de suas redes de ensino

Nesta perspectiva, o Conselho Nacional dos Procuradores Gerais emitiu nota técnica com o fim de sugerir aos membros do Ministério Público especializados na defesa do direito à educação o acompanhamento das providências adotadas pelos sistemas de ensino durante o período de aplicação das medidas de prevenção ao contágio e enfrentamento da propagação do novo Coronavírus (COVID-19). Assim, o Órgão Ministerial adotou conduta proativa em 
matéria de políticas de educação, por meio de Procedimento Administrativo próprio, onde poderão ser atendidas as ações em defesa à educação, dentre elas (CONSELHO NACIONAL OS PROCURADORES GERAIS, 2020):

a) Participação em debates e discussões dos sistemas de ensino com relação a retomada das aulas, buscando a necessidade de que o retorno dos alunos ocorra de forma gradual, com acolhimento dos sentimentos de perda em razão da doença e da morte de amigos e familiares vitimados pela COVID-19, com base nos princípios constitucionais implícitos da solidariedade e da fraternidade, trabalhando os aspectos psicológicos e sociológicos que envolvem a situação, preparando materialmente as escolas para esse retorno, estabelecendo critérios rigorosos, humanos, materiais (condições de infraestrutura dos espaços pedagógicos), sanitários e pedagógicos para a volta dos alunos às escolas;

b) Dentre outros esclarecimentos, que o Conselho Estadual/Municipal de Educação e Secretários de Educação acerca da adoção de plano de ação de educação domiciliar para alunos com problemas de saúde e em situação de risco, em razão da Covid-19, haja vista o tempo em que poderão ficar afastados das salas de aula, mesmo quando do retorno às aulas presenciais (tanto na rede pública de ensino como na rede particular);

c) Esclarecimentos, diante da opção dos sistemas por atividades não presenciais, sobre a necessidade de utilização de meios e recursos diversificados, para além do uso de ferramentas tecnológicas, de modo a fazer frente às desigualdades no uso da tecnologia pelos alunos e permitir 18 o acesso de todos ao conteúdo disponibilizado, assim como às orientações pedagógicas dos professores habilitados;

d) Análise sobre a existência e formulação de políticas que estimulem a continuidade da manutenção de vínculos entre professores e alunos, intensificando ações de cuidado e acompanhamento, sobretudo em casos envolvendo situações de alta vulnerabilidade social;

e) Análise se os sistemas de ensino e as escolas trataram de forma diferenciada e eficaz no sentido de contemplar os princípios constitucionais educacionais da universalidade, da equidade e da qualidade, a Educação de Jovens e Adultos, a Educação Especial, a Educação Indígena, a Educação Quilombola, a Educação do Campo e a Educação nos Sistemas Prisionais e Socioeducativo, considerando as suas especificidades;

f) Acompanhamento, no retorno às aulas presenciais, de eventual necessidade de nova readequação dos calendários escolares, com a elaboração de protocolos pedagógicos que contemplem a reposição de conteúdos eventualmente abordados em atividades não 
presenciais, se demonstrado que as deficiências na garantia de acesso aos meios e recursos (especialmente tecnológicos) disponibilizados pelas redes de ensino tenham prejudicado o direito à aprendizagem em igualdade de condições para todos os alunos, além de protocolos sanitários que deverão ser atestados pelo órgão sanitário estatal, evitando grande aglomeração de pessoas, com a exigência de preparação física e sanitária das escolas, capacitação dos profissionais da educação, até a adequada orientação aos alunos e pais, quanto à prevenção da disseminação do coronavírus;

g) Acompanhamento das estratégias para a realização de busca ativa dos alunos eventualmente evadidos, com o consequente planejamento de suas atividades escolares a partir do retorno;

h) Fomento da garantia do direito à informação e a transparência mediante a criação de canais de comunicação entre os responsáveis pelos sistemas de ensino/escolas e os pais, informando as metodologias adotadas e suas formas de avaliação, bem como viabilizando o recebimento de denúncias e reclamações.

Além dessa proteção encabeçada pelo Conselho Nacional dos Procuradores Gerais, embora timidamente, o Ministério da Educação tem visualizado medidas priorize o direito à educação.

Deste modo, diante da Emergência em Saúde Pública de Importância Nacional (ESPIN) em decorrência da Infecção Humana pelo novo coronavírus (Covid-19), observada diante da Portaria GM/MS n ${ }^{\circ}$ 188, de 3 de fevereiro de 2020, a qual instituiu protocolos diante de contaminações experimentada no Brasil no momento de pandemia, o Ministério da Educação (MEC) disponibilizou o Painel de Monitoramento da Educação Básica no Contexto da Pandemia. (BRASIL, 2021).

$\mathrm{Na}$ referida plataforma é possível averiguar informações sobre a situação emergencial na qual o país passa a respeito da educação básica pública. $O$ instrumento tecnológico aponta dados quantitativos necessários a tomada de decisões em políticas públicas educacionais destinadas a gestores públicos municipais e estaduais, além de direcionar diretores e demais supervisores diante do contexto de pandemia causado pela Covid-19.

O objetivo do Painel é servir como uma solução tecnológica, auxiliando dirigentes municipais e secretários estaduais de educação, bem como diretores escolares, na tomada de decisões, no contexto da pandemia da Covid-19. Outra finalidade do painel é informar a sociedade sobre os possíveis problemas a serem elencados pela educação básica. 
Ocorre que os dados apenas apontam o quantitativo de alunos matriculados, total de escolas, quantitativo de alunos matriculados em escolas públicas e escolas privadas. Não fazem a correlação com casos de Covid-19 e alunos matriculados. Logo, trata-se de uma solução tecnológica que não está sendo utilizada em toda suas possíveis potencialidades, o que impede decisões estratégicas pelos agentes cabíveis.

Outra postura adotada em política pública governamental em perspectiva de garantia ao direito á educação, o Ministério da Educação homologou parecer do Conselho Nacional de Educação-CNE permitindo a continuidade das aulas remotas no Ensino Básico e Superior enquanto perdurar a pandemia. A postura em comento apresenta-se como única alternativa para consecução do direito à educação. Contudo, não se sabe se o perseguido direito à educação será concedido substancialmente para todos os sistemas de ensino federal, estaduais, distrital e municipais, nas instituições escolares públicas, privadas, comunitárias e, também, confessionais.

No que tange ao referido tema, artigo 31 da decisão do CNE aponta (BRASIL, 2021):

Parágrafo único. As atividades pedagógicas não presenciais poderão ser utilizadas de forma integral nos casos de:

I - suspensão das atividades letivas presenciais por determinação das autoridades locais; e

II - condições sanitárias locais que tragam riscos à segurança das atividades letivas presenciais.

O fato é que antes da pandemia, as escolas não ofertavam dignamente a acepção substancial do direito à educação. Muitas não contavam com infraestrutura básica, tão pouco ambientes salubres, forma de ensino atrativo. Mas a Constituição Federativa do Brasil já apontava desde 1988 o direito à educação como uma verdadeira forma de empodera-se de direitos, visto que concede aos cidadãos o desenvolvimento de outros direitos, além de desenvolvimento da inteligência e, consequentemente da autonomia.

Proteger o direito à educação em tempo de pandemia significa tratar a dimensão substancial da democracia. Para Copetti Neto (2016) a fundamentação democrática garantista encontra seu substrato na ideia de estado para os direitos. Nele, o espaço destinado aqueles direitos compreendidos como vitais assume a conotação essencial de estado “(..) cuja vinculação à soberania popular se estabelece pelo molde em que todos os homens são desses os únicos titulares, o que acaba, desse nodo, por subscrever e direcionar a democracia.”. assim, a democracia é consubstanciada contra restaurações e repressões que tendencialmente 
visem buscar a instrumentalização ou a subversão do conjunto de garantias constitucionais que são destinadas à proteção da igualdade de todos em direitos.

Deste modo, é inviável a discricionariedade administrativa na democracia constitucional, no que se refere especialmente à prestação de direitos sociais, tal qual o direito à educação. Ainda é tímida a proteção, em momento de pandemia, do substancial direito á educação, qual seja, a busca efetiva se crianças e adolescentes estão, de fato, tendo direito a uma garantia superior e essencial à convivência humana, como um direito venerável de todo ser humano, necessário ao desenvolvimento pleno das habilidades físicas, intelectuais e valorativos do homem.

Assim, a democracia social dentro de uma perspectiva do garantismo jurídico visa diminuir a exposição maciça e a dependência dos direitos sociais, tanto em relação á discricionaridade administrativa ou até mesmo quanto à regra da maioria, no que se refere às pressões de mercado. Isso porque os direitos sociais, tal quela o direito à educação é um direito fundamental de todo homem, visto que são indisponíveis, inalienáveis, inalteráveis e invioláveis mesmo no contexto de pandemia.

\section{CONSIDERAÇÕES FINAIS}

Este estudo buscou apresentar e descrever o trato dado à educação, direito humano fundamental, pelo Brasil diante da situação emergencial de enfrentamento ao coronavírus e que evidenciaram uma preocupação com a maneira como cada um dos países direcionaram as suas ações, sobretudo normativas, visando assegurar a continuidade do acesso, permanência e qualidade da educação básica formal.

Para o alcance das pretensões, partiu-se do levantamento bibliográfico e documental, observando-se a construção multidimensional e as características do direito à educação, bem como o reconhecimento de sua relevância para a construção de uma sociedade igualitária, livre, justa e democrática. Reuniu-se também documentos nacionais para verificar como cada um dos países tratam os objetivos e fundamentos da educação em sua constituição e legislação infraconstitucional.

Apresentou-se o cenário de crise sanitária instalado pelo COVID-19, com os riscos que a sua contaminação e expansão representam para a saúde humana, de modo a localizar o leitor em relação ao quadro emergencial que clamou pelo distanciamento social e, dentre outras medidas, determinou a suspensão das aulas presenciais. 
A situação descrita implica na criação de estratégias diversas. De forma que este estudo demonstrou que, apesar das particularidades diversas apresentadas pelo Brasil, no aspecto econômico, social, demográfico e etc., os documentos suscitados demonstram a mesma preocupação: a utilização de ferramentas tecnológicas que garantam a continuidade do ensino e que não comprometam o ano letivo. Quer dizer, a atenção dada às instruções sanitárias, seguem sendo observadas.

Outro ponto de destaque se relaciona ao reconhecimento de uma tarefa árdua e trabalhosa, com obstáculos a serem vencidos, sobretudo quando se pensa que, em países com diferenças sociais tão amplas, como os escolhidos, o alcance universal e igualitário a todos os alunos e alunas é um desafio.

Cabe ressaltar que a educação deve ser analisada como um componente para o desenvolvimento humano. Sendo assim, a educação é um componente basilar para a socialização, assunção de responsabilidade e convivência social. O processo educacional conduz a efeitos gradativos na vida do ser humano. Desde modo, diante do estado pandêmico que alcança em demasia o Brasil, o direito a educação não pode ficar estático e submetido a pontuais ações estratégicas do estado brasileiro, sob pena de não se construir em terras brasileiras um estado para o direito, como o direito à educação.

Desta feita, as estratégias adotadas tem sido semelhantes com a distribuição de equipamentos (celular e computador), acesso à internet, e emprego de redes sociais, plataformas digitais e distribuição de material impresso, por exemplo. A preocupação com a formação docente, por seu turno, é um aspecto a ser destacado. Já que os profissionais foram convidados, em tempo record a se capacitar para o manuseio da tecnologia.

Nesse sentido, os regramentos legais tem sido criados a fim de assegurar o direito à educação. Entretanto, uma avaliação mais específica e ponderada dos resultados deixados por toda essa situação poderão ser melhor sentidos e analisados no futuro. Enquanto isso, adequadamente as estratégias de retorno, a readequação com a rotina escolar, a higiene, alimentação, quantidade de alunos por turma, a limitação do espaço físico precisará ser considerada para que este retorno aconteça de forma segura, sem que comprometa a saúde do corpo escolar como um todo.

\section{REFERÊNCIAS}

BOBBIO, Noberto. A Era do Direitos. São Paulo: Campos, 2004. 
BRASIL. Base Nacional Comum Curricular (BNCC). Ministério da Educação: 2018. Disponível em:

http://basenacionalcomum.mec.gov.br/images/BNCC_EI_EF_110518_versaofinal_site.pdf. Acesso em 10 nov. 2020.

BRASIL. Constituição da República Federativa do Brasil, de 05 de outubro de 1988.

Disponível em:

<http://www.planalto.gov.br/ccivil_03/constituicao/constitui\%C3\%A7ao.htm>. Acesso em: 05 nov. 2020.

BRASIL. LEI No 4.024, de 20 de dezembro de 1961. Fixa as Diretrizes e Bases da Educação Nacional. 1961. Disponível em:

http://www.planalto.gov.br/ccivil_03/leis/14024.htm. Acesso em: 05 nov. 2020.

BRASIL. LEI No 9.394, de 20 de dezembro de 1996. Estabelece as diretrizes e bases da educação nacional. Disponível em: http://www.planalto.gov.br/ccivil_03/leis/19394.htm. Acesso em: 05 nov. 2020.

BRASIL. LEI No 11.947, de 16 de junho de 2009. Dispõe sobre o atendimento da alimentação escolar e do Programa Dinheiro Direto na Escola aos alunos da educação básica; altera as Leis nos 10.880, de 9 de junho de 2004, 11.273, de 6 de fevereiro de 2006, 11.507, de 20 de julho de 2007; revoga dispositivos da Medida Provisória no 2.17836, de 24 de agosto de 2001, e a Lei no 8.913, de 12 de julho de 1994; e dá outras providências. Disponível em: http://www.planalto.gov.br/ccivil_03/leis/19394.htm. Acesso em: 05 nov. 2020.

BRASIL. Medida Provisória $\mathbf{n}^{\circ}$ 934, de $1^{\text { }}$ de abril de 2020. Disponível em: http://www.planalto.gov.br/ccivil_03/_ato2019-2022/2020/mpv/mpv934.htm. Acesso em: 05 nov. 2020.

BRASIL. Ministério da Educação. MEC lança Painel de Monitoramento da Educação Básica no Contexto da Pandemia. Disponível em: https://www.gov.br/mec/ptbr/assuntos/noticias/mec-lanca-painel-de-monitoramento-da-educacao-basica-no-contexto-dapandemia. Acesso em 15 abr 2021.

Conselho Nacional dos Procuradores Gerais. Nota técnica-2020 CNPG/GNDH/COPEDUC. Dispõe sobre ao direito à educação. Normas gerais aplicáveis a educação durante a pandemia da COVID-19. Reordenação do ano letivo para a educação básica. Critérios para a validade do ensino não presencial para fins de efetividade dos dias letivos. Orientações para atuação do Ministério Público brasileiro. Disponível em: .file:///C:/Users/viviane.lima/Downloads/NOTA\%20TECNICA\%20COPEDUC\%20COVID $\% 2019 \% 20$ CALENDARIO\%20ESCOLAR-1-1-1.pdf.

COMPARATO, Fabio Konder. A afirmação histórica dos Direitos Humanos. 5. ed. São Paulo: Saraiva: 2007. 
COPETTI NETO, Alfredo. A democracia constitucional sob o olar do garantismo jurídico. Cord. Alfredo Copetti Neto, Alexandre Morais da Rosa. 1 ed. Florianópolis, SC: Empório do Direito, 2016.

DIAS, Adelaide Alves. Da educação como direito humano aos direitos humanos como princípio educativo. In: Educação em Direitos Humanos: fundamentos teóricometodológicos. João Pessoa: Editora Universitária, 2007. p. 441-456.

FERREIRA FILHO, Manoel Gonçalves. Direitos humanos fundamentais. 11. ed. rev. e amp. São Paulo: Saraiva, 2009.

GIL, Antônio Carlos. Métodos e técnicas de pesquisa social. 6. ed. São Paulo: Atlas, 2008.

INSTITUTO RUI BARBOSA. A Educação não pode esperar. 2020. Disponível em: https://irbcontas.org.br/tag/a-educacao-nao-pode-esperar/. Acesso em: 12 out. 2020.

\section{INSTITUTO NACIONAL DE ESTUDOS E PESQUISAS EDUCACIONAIS ANÍSIO} TEIXEIRA-INEP. Censo da Educação Básica 2020 - resumo técnico.

Disponível em: http://inep.gov.br/informacao-da-publicacao//asset_publisher/6JYIsGMAMkW1/document/id/6993007. Acesso em 15 abr 2021.

HUANG, Chaolin et al. Clinical features of patients infected with 2019 novel coronavirus in Wuhan, China. The Lancet, [s.1.], v. 395, n. 10223, p. 497-506, fev. 2020. Disponível em: <https://www.thelancet.com/action/showPdf?pii=S0140-6736\%2820\%2930183-5>. Acesso em: 12 out. 2020.

LYRA FILHO, Roberto. Por um Direito sem dogmas. Porto Alegre: Fabris, 1980.

MINISTÉRIO DA EDUCAÇÃO. CONSELHO NACIONAL DE EDUCAÇÃO. Parecer CP n. 5/2020. 2020a. Disponível em: http://portal.mec.gov.br/conselho-nacional-deeducacao/atos-normativos--sumulas-pareceres-e-resolucoes/33371-cne-conselho-nacional-deeducacao/85201-parecer-cp-

2020\#: :text=Parecer\%20CNE\%2FCP\%20n\%C2\%BA\%205,da\%20Pandemia\%20da\%20CO VID\%2D19. Acesso em: 12 out. 2020.

MINISTÉRIO DA EDUCAÇÃO. CONSELHO NACIONAL DE EDUCAÇÃO. Parecer CP n. 9/2020. 2020b. Disponível em:

http://portal.mec.gov.br/index.php?option=com_docman\&view=download\&alias=147041 pcp009-20\&category_slug=junho-2020-pdf\&Itemid=30192. Acesso em: 12 out. 2020.

MINISTÉRIO DA EDUCAÇÃO. CONSELHO NACIONAL DE EDUCAÇÃO. Parecer CP n. 11/2020c. 2020. Disponível em:

http://portal.mec.gov.br/index.php?option=com_docman\&view=download\&alias=148391 pcp011-20\&category_slug=julho-2020-pdf\&Itemid=30192. Acesso em: 12 out. 2020.

MINISTÉRIO DA EDUCAÇÃO. CONSELHO NACIONAL DE EDUCAÇÃO. Parecer CP n. 15/2020. 2020d. Disponível em: 
http://portal.mec.gov.br/index.php?option=com_docman\&view=download\&alias=160391pcp015-20\&category_slug=outubro-2020-pdf\&Itemid=30192. Acesso em: 12 out. 2020.

MINISTÉRIO DA SAÚDE. PORTARIA nº 188, de 3 de fevereiro de 2020. Declara Emergência em Saúde Pública de importância Nacional (ESPIN) em decorrência da Infecção Humana pelo novo Coronavírus (2019-nCoV). 2020. Disponível em: http://bvsms.saude.gov.br/bvs/saudelegis/gm/2020/prt0188_04_02_2020.html. Acesso em: 10 nov. 2020.

ORGANIZAÇÃO DAS NAÇÕES UNIDAS (ONU). Declaração Universal dos Direitos Humanos. Paris: ONU, 1948. Disponível em: http://www.ohchr.org/EN/UDHR/Documents/UDHR_Translations/por.pdf. Acesso em: 15 out 2020.

ORGANIZAÇÃO MUNDIAL DE SAÚDE. WHO Director-General's statement on IHR Emergency Committee on Novel Coronavirus (2019-nCoV). Disponível em: https://www.who.int/dg/speeches/detail/who-director-general-s-statement-on-ihr-emergencycommittee-on-novel-coronavirus-(2019-ncov). Acesso em: 10 nov. 2020.

PNUD. PNUD apresenta Relatório de Desenvolvimento Humano 2019 com dados de 189 países. 2019. Disponível em:

https://www.br.undp.org/content/brazil/pt/home/presscenter/articles/2019/pnud-apresentarelatorio-de-desenvolvimento-humano-2019-com-

dado.html\#: :text=Dados\%20do\%20Brasil\&text=Esse $\% 20$ resultado $\% 20$ mant $\% \mathrm{C} 3 \% \mathrm{~A} 9 \mathrm{~m} \% 20 \mathrm{o}$ \%20Brasil,e\%20Uruguai\%20aparecem\%20na\%20frente. Acesso em 20 nov. 2020.

RAMOS, André de Carvalho. Curso de direitos humanos. 2 ed. rev., atual. e ampl. São Paulo: Saraiva, 2015.

SARLET, Ingo Wolfgang. A eficácia dos direitos fundamentais: uma teoria geral dos direitos fundamentais na perspectiva constitucional. 11. ed. rev. atual. Porto Alegre: Livraria do Advogado Editora, 2012. 